\title{
EDITORIAL
}

\section{Scientific Certitude}

\section{Stephen E. Braude}

https://doi.org/10.31275/20201971

Creative Commons License CC-BY-NC

I've been both fascinated and distressed by the arguments raging over how best to respond to the covid-19 pandemic. In particular, l've been struck by the way people claim scientific authority for their confident assurances of what needs to be done. And I'm especially intrigued by the scorn

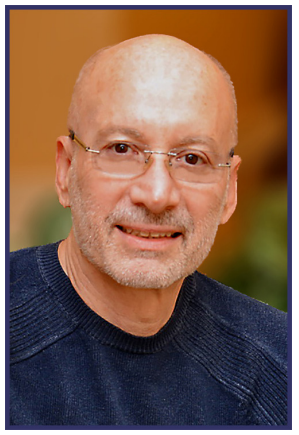
they often lavish on those who hold differing views on what science is telling us. The heat generated by the resulting debates is strikingly similar to the heat generated by debates over the science connected with human-caused climate change. And in both cases, the disputants too often presuppose indefensibly naïve views about scientific authority and certitude, apparently unaware that even the allegedly most obvious logical truths lack the certainty attributed to scientific authority in these debates.

As a rule, I dislike re-circulating my Editorials, but I think it's time to resurrect one (modestly tweaked) from a few years ago (Braude, 2017), addressing precisely this issue.

Man is a rational animal who always loses his temper

when he is called upon to act in accordance with the dictates of reason.

-Oscar Wilde

I've often noticed how debates within the SSE community sometimes parallel debates in the political arena, perhaps especially with respect to the passion they elicit and the intolerance and condescension sometimes lavished on members of the "opposition." Occasionally, of course, the debates in the SSE are nearly indistinguishable from those 
in the political arena-say, over the evidence for human-caused climate change. But what I find most striking is how the passion, intolerance, etc.- - perhaps most often displayed by those defending whatever the "received" view happens to be-betrays either a surprising ignorance or else a seemingly convenient lapse of memory, one that probably wouldn't appear in less emotionally charged contexts. What impassioned partisans tend to ignore or forget concerns (a) the tentative nature of both scientific pronouncements and knowledge claims generally (including matters ostensibly much more secure than those under debate), as well as (b) the extensive network of assumptions on which every knowledge claim rests.

So l'd like to offer what I hope will be a perspective-enhancer, concerning how even our allegedly most secure and fundamental pieces of a priori knowledge are themselves open to reasonable debate. A widespread, but naïve, view of logic is that no rational person could doubt its elementary laws. But that bit of popular "wisdom" is demonstrably false. And if that's the case, then so much the worse for the degree of certitude we can expect in more controversial arenas. Let me illustrate with a few examples. ${ }^{1}$

Consider, first, an empirical context in which some have tried to deploy a logical law. In philosophical discussions of the nature and structure of the self, many writers invoke an alleged version of the law of non-contradiction to argue for the existence of distinct parts of the self. This strategy is at least as old as Plato and may be more familiar to JSE readers in the form it took with Freud. Ironically, though, these arguments highlight just how insecure this dialectical strategy is (for a more detailed account, see Braude, 1995, Chapter 6).

Consider: In debates about the nature of multiple personality/ dissociative identity disorder (MPD/DID), many argue that because different alter personalities/identities can apparently have different and even conflicting epistemic states, the self must have distinct parts that correspond to those conflicting states. For example, Kathleen Wilkes writes:

We break this law [of non-contradiction] as soon as we permit ourselves to say that one and the same entity both knows and does not know that $p$, for nothing can, at time $t$, be said to $\varphi$ and not to $\varphi$. (Wilkes, 1988, 142) 
Of course, to those without any philosophical axe to grind, cases of DID might suggest that one can indeed be said to $\varphi$ and not to $\varphi$ at the same time. ${ }^{2}$ Since that could easily be taken to suggest that the law of noncontradiction has some hitherto unacknowledged limitation, and since one must always be open to the possibility that logical laws have limitations of one sort or another, let's examine the status of the law which some dissociative and other phenomena appear to violate.

Notice, first, that what logicians generally consider to be the law of noncontradiction is either (a) the formal, syntactic law " $\sim(A \cdot \sim A)$," usually rendered more informally as "not-( $A$ and not- $A)$," or else (b) a claim in logical semantics about truth-value assignments-namely, "no sentence can be both true and false" (or alternatively, "the conjunction of any sentence $p$ and its denial not- $p$ is false"). But the first of these is not violated by dissociative conflicts, and the second is not even clearly a law.

Consider the syntactic law first. It concerns the form, rather than the content, of strings of symbols within a formal system. It takes any compound expression of the form "not-( $A$ and not- $A$ )" to be a theorem, for any well-formed formula " $A$ ". But strictly speaking, the law doesn't pertain to sentences of any actual natural language. The syntactic law of noncontradiction does nothing more than sanction a particular arrangement of expressions within a certain set of formal systems. And although one can easily determine which symbolic expressions are theorems, those logical systems don't, in addition, offer a decision procedure for determining which sentences in a natural language are true or false. On the contrary, the relationship of formal to natural languages has to be both stipulated and investigated. And ultimately, the utility of a formal system of logic must be evaluated empirically, by seeing whether or how well it applies to various domains of discourse-for example, by seeing whether the truth-values it would assign to actual sentences matches our independent judgments about what those truth-values should be.

In fact, formal logical systems don't even specify which expressions in a natural language count as legitimate instances of a simple (i.e., noncompound) formula " $A$ "-hence, which natural language expressions are instances (or violations) of its theorems. Although logicians generally agree that the simple formulae of the systems should 
represent declarative sentences, there's considerable debate over which particular kinds of declarative sentences are suitable. Interestingly, many would say that as far as the purely formal laws of logic are concerned, " $A$ " could stand even for sentences whose truth-value or meaning are indeterminate, such as "unicorns are compassionate," "the square root of 4 is asleep," and "Zeus is insecure." But then it seems as if the uninterpreted formal law of noncontradiction is simply irrelevant to the cases under consideration. At best, those cases appear to challenge a semantic counterpart to the formal law, either

$\left(N C_{1}\right)$ : The conjunction of any sentence $p$ and its denial not- $p$ is false

or

$\left(\mathrm{NC}_{2}\right)$ : No sentence can be both true and false

We needn't worry at the moment about whether (or to what extent) either of these versions of the law of noncontradiction is satisfactory. What matters now is that even if the law of noncontradiction turns out to be a viable principle of logical semantics, it may still have a variety of significant limitations. In fact, the utility of formal logical laws varies widely, and the interpretation of those laws has proven to be a notoriously tricky business. As with all formal systems, no system of logic determines in which domains (if any) its expressions may be successfully applied. Students of elementary logic learn quickly that there are differences between the logical connectives "and" and "or" and many instances of the words "and" and "or" in ordinary language. Similarly, not all "if...then..." sentences are adequately handled by the material conditional in standard systems of sentential logic, although that logical connective is undeniably useful in a great range of cases. Moreover, varieties of nonstandard and "modal" logics have been developed in attempts to represent types of discourse resistant to standard logical systems.

But even more relevantly, in most standard systems of logic, the formal law of noncontradiction, "not-( $A$ and not- $A)$," is demonstrably equivalent to the law of the excluded middle, " $A \vee \sim A$ " (i.e., "A or not- $A$ "). Like the formal law of noncontradiction, the law of the excluded middle concerns the form rather than the content of expressions. It takes any 
compound formula of the form "A or not- $A$ " to be a theorem (or logical truth), no matter what formula " $A$ " happens to be. Now the semantic sibling of the syntactic law of the excluded middle is called the law of bivalence, which states that every sentence is either true or false. But the law of bivalence has faced numerous challenges throughout the history of logic (in fact, since the time of Aristotle). Many have argued that it fails for sentences in the future tense and sentences whose singular terms refer to nonexistent objects. Moreover, some logicians consider these difficulties sufficiently profound to warrant the development of logical systems that retain the syntactic law of the excluded middle but reject the semantic law of bivalence (see, e.g., van Fraassen, 1966, 1968; Thomason, 1970). Now granted, these same logicians don't also reject the semantic version of the law of noncontradiction. Nevertheless, their reservations concerning bivalence should give us pause (especially in light of the caveats noted above regarding the limitations of formal systems generally). The debate over bivalence illustrates an important point-namely, that the relative impregnability of a formal logical law may not be inherited by its semantic counterpart(i.e. one of its interpretations). But at the very best, it's only the semantic counterpart of noncontradiction that rests at the center of the Platonic/Freudian arguments for parts of the self. And in fact, as far as Plato's argument for the parts of the soul is concerned, the argument turns on an even more exotic interpretation of noncontradiction (see Braude, 1995, for details).

But before we leave this topic, it's important to note that

$\left(N C_{1}\right)$ : The conjunction of any sentence $p$ and its denial not- $p$ is false and

$\left(\mathrm{NC}_{2}\right)$ : No sentence can be both true and false

are likewise problematical, and probably more so than most JSE readers appreciate. First of all, $\left(\mathrm{NC}_{1}\right)$ has numerous counterexamples familiar to students of logic and the philosophy of language. For example, it seems to fail for sentences such as the aforementioned "unicorns are compassionate," "the square root of 4 is asleep," and "Zeus is insecure," which seem to lack truth-value. Many (but, notably, not all) would say 
that when a sentence lacks truth-value, the conjunction of that sentence and its denial also lacks truth-value.

The somewhat more common $\left(\mathrm{NC}_{2}\right.$ ) has similar problems. Most notoriously, perhaps, it fails for the self-referential sentence "this sentence is false," as well as for kindred expressions that don't seem even remotely suspicious inherently. For example, it fails for the innocent "the sentence on page 42 is false," when that sentence happens to be the only sentence on page 42 . If these sentences have any truth-value at all, it seems as if they will be both true and false.

Furthermore, $\left(\mathrm{NC}_{2}\right)$ apparently fails for quite mundane presenttense sentences. For example, "Socrates is sitting" may be true at one time and false at another. Of course, one standard response to such cases would be to claim that the sentence "Socrates is sitting" contains an implicit reference to its time of production, so that it's not really the same sentence that's true at one time and false at another (i.e., those non-simultaneous sentences would allegedly differ in meaning or express different propositions). For reasons too complex to be explored here, it seems to me that this particular maneuver creates more problems than it solves. Indeed, I've argued that the standard Aristotelian notion of contradictories (stated in terms of opposing truth-values) fails conspicuously for a tensed natural language, and that tensed contradictories can have the same truth-value (see Braude, 1986, for a discussion of these issues). Although I recognize that my position is most definitely a minority view, I submit that there are additional serious reasons here for challenging the straightforward application of $\left(\mathrm{NC}_{2}\right)$ to a real natural language- - hence, for questioning its inviolability outside of the highly artificial or overly simplified linguistic situations to which logical laws apply easily. In any case, this nest of issues illustrates again the kinds of substantive and difficult-toresolve concerns involved in evaluating what many consider to be our most cherished logical principles.

Please note that my point is not that the semantic law of noncontradiction is useless as a philosophical tool. And the moral is not simply that logical laws (like formal laws generally) may not hold in all domains (although that's certainly true and relevant here). Rather, the point is also that logical laws hold in real life only for sentences we regard as acceptable (or legitimate) and appropriate, or as understood 
in certain ways rather than others. But these interpretations and classifications of linguistic entities are practical decisions, made as part of a much larger network of interrelated philosophical commitments. Accordingly, those decisions don't stand or fall in isolation from others in various areas of philosophy and logic. In fact, they will continually be open for reassessment in light of apparent difficulties arising at numerous points in our overall system of commitments.

One further example reinforces that last point; it concerns an allegedly fundamental principle about what philosophers call numerical identity. Many have argued that it's an indisputable rational principle that each thing is identical with itself. However, it turns out that the concept of numerical identity is not so straightforward.

To see this, consider first the expression

$$
(x)(x=x)
$$

usually interpreted as "anything $\mathrm{x}$ is such that it's identical to itself," or more colloquially, "everything is self-identical." The acceptability of this alleged law of identity is not something we can decide by considering that law alone, and it's certainly not something that's immune from debate among reasonable and well-informed persons. Regarded merely as a theorem of a formal system, it has no meaning at all; it's nothing more than a sanctioned expression within a set of rules for manipulating symbols. But as an interpreted bit of formalism, it's acceptable only with respect to situations in which we attempt to apply it. And perhaps more interesting, it's intelligible only as part of a larger network of commitments. That is, what we mean by "everything is selfidentical" depends in part on how we integrate that sentence with other principles or inferences we accept or reject.

To see this, consider whether we would accept as true the statement

(1) Zeus = Zeus

To many, no doubt, that sentence seems as un problematically true as the superficially similar

(2) Steve Braude $=$ Steve Braude 
However, in many systems of deductive logic containing the rule of Existential Generalization (EG), from the symbolization of (1)—namely,

$\left(1^{\prime}\right) z=z$

we can infer

(3) (马x) $\mathrm{x}=\mathrm{z}$

which we typically read as

(4) Zeus exists.

And of course, many consider that result intolerable.

Not surprisingly, philosophers have entertained various ways of dealing with this situation. One would be to taxonomize different types of existence and interpret the rule of Existential Generalization as applying only to some of them (for example, prohibiting its application to cases of mythical or fictional existence). Another approach would be to get fussy about the concept of a name. We could decide that "Zeus" is not a genuine name and that genuine names (like "Steve Braude") pick out only real existent individuals, and not (say) mythical or fictional individuals. (Readers might be especially surprised to learn that some have actually endorsed the view that we should not consider "Hamlet" or "Zeus" to be names when they pick out fictional or mythical characters.) In any case, both these approaches concede certain (but different) sorts of limitations to standard predicate logic and the way or extent it connects with ordinary discourse. Others prefer to tweak the logic directly, either syntactically or semantically. For example, some simply reject the rule of Existential Generalization and endorse a socalled (existence) free logic. Alternatively, some retain EG but adopt a substitutional interpretation of the quantifiers "( $\mathrm{x})$ " and "(सx)," so that instead of reading (3) as

$\left(3^{\prime}\right)$ There is (or exists) some $x$ such that $x$ is identical with $z$ (Zeus)

we read it as

$\left(3^{\prime \prime}\right)$ Some substitution instance of " $x=z$ " is true. 
The latter, they would say, is acceptable and carries no existential commitments. ${ }^{3}$

Now the reader needn't understand all these options. However, the moral should be clear enough, and it's not simply that these approaches raise concerns about what we can legitimately regard as a thing. What matters here is that the statement "everything is identical to itself" is not as clear or indisputable as one might think, and even more important in the present context, it's not simply true no matter what. Its truth (and indeed, meaning) turn out to be deeply conditional (rather than categorical), because they're inextricably linked to other principles or inferences we regard as acceptable, and that whole package of decisions can only be evaluated on pragmatic grounds. That's why it's perfectly respectable to decide that some solutions (say, to puzzles about identity) are appropriate for some situations and that other solutions are appropriate for others. We're not obligated to find a one-size-fits-all solution, and we're never constrained to select one solution or (context of inquiry) as privileged or fundamental.

The reason why l've gone on at such length about these matters is that they should serve as a cautionary note to those who all too easily display intolerance and condescension in empirical (or political) debates. It's completely clear that reasonable and informed people can disagree (and have disagreed) over the nature and status—and, indeed, the meaning - of what we take to be fundamental logical laws. Of course, scientific (and political) debates rest not only on logical assumptions but on various empirical and methodological assumptions as well. So presumably they're even more contentious and vulnerable to reasonable challenges than disputes over the foundations of logic. But then one would expect to find even more room there for reasonable and informed disagreement. Ideally, then, one would expect participants in scientific debates to be particularly open-minded, tolerant, and respectful of opposing views. So the next time you find yourself tempted to dismiss or deride with a disdainful flourish someone with whom you disagree over a matter of science (or politics), I encourage you to remember how venerable and substantive are the serious debates over the very foundations of our conceptual framework. 
Finally (to return to covid-19), and quite apart from the foregoing mini-treatise on a priori knowledge, I should mention that SSE members need to be especially vigilant about making simplistic appeals to "what the science shows." Indeed, SSE members should know this as well as anyone. Probably every SSE member has an interest in phenomena disparaged by scientific orthodoxy, and probably every SSE member recognizes that science is conducted by fallible, and indeed corruptible and sometimes reprehensible, human beings. So you'd think that members of our community would be among the first to acknowledge the provisional nature of science generally and the history of scientific change and scientific error. Moreover, you'd think they would be among the first to be wary of confident scientific pronouncements made about areas deeply permeated by competing political and financial interests.

But perhaps most important, we don't get a free pass to complain about the fallibility and (more than occasional?) dishonesty of scientific orthodoxy when it comes to our interests in psi, LENR, UFOs, or cryptozoology, and then contemptuously disparage qualified people who hold opinions contrary to ours on (say) climate change or covid-19. I believe we should be careful not to adopt the complacent or condescending attitude we so proudly and self-righteously attack in our publications and conferences. And we should smell danger immediately when ostensibly empirical disagreements generate a great deal of emotional heat. That's a situation that clearly calls for caution, not dogmatism.

So I urge SSE members to be consistent in their confidence in science. If you're so ready to challenge received science when it comes to LENR, unidentified aerial phenomena, sea monsters, or psi, it's presumably because you realize that science is conducted by imperfect human beings, who often enough in the past have been driven by lessthan-admirable motives, or who were simply victims of mere confusion. But then you forfeit the authority to be snotty and condescending about those who disagree with your views on human-caused climate change, or the nature and status of covid-19. Like it or not, those are areas about which competent and informed people do in fact disagree. So I say you should be among the first to be open to reasoned and serious minority opinion, and among the last to be dictatorial about what the science shows. 
Since this is the holiday season and an appropriate time for wallowing in weltschmerz and reflecting on the year that's coming to a close, l'd like once again to acknowledge and thank our dedicated and overworked team of Associate Editors and the many reviewers on whom we rely in vetting papers for inclusion in the JSE. As I've noted before, producing this Journal poses a distinctive challenge. Because the JSE deals with topics either shunned altogether or dealt with shabbily by more mainstream publications, the community of qualified readers for high-level peer review is quite small. Ideally, I'd prefer to have a larger team of Associate Editors, in order to lighten the editorial load for those who-perhaps inscrutably_continue to volunteer large chunks of time to shepherding submissions through our system. However, adding members to that team inevitably subtracts from the small pool of qualified referees. So I'm deeply grateful to my largely behind-thescenes Associate Editors, who realize the need to maintain the high standard of scientific and scholarly excellence that's characterized the JSE since its inception, who recognize that there are only so many people on whom the JSE can rely, and who accordingly and generously donate their valuable time. I'm equally grateful to our many referees, many of whom we call upon over and over, simply because they have expertise in the relevant areas of research, and because the number of open-minded people who have that expertise remains depressingly small.

I must also express my deep appreciation for the breathtaking efficiency, technical panache, and thorough understanding of the publishing business of our Managing Editor, Kathleen Erickson. And although her usual responsibilities are daunting enough, this year my editorial team and I have needed Kathleen to help us navigate a new, user-unfriendly online system for handling submissions, evidently created by graduates of the Marquis de Sade School of Computer Programming. But fortunately, Kathleen handles our complaints and cries of outrage (or as my wife would say, our booing and hooing) promptly, effectively, and with remarkable equanimity. I'm sure JSE's Associate Editors and referees agree with me on the pleasure and comfort of having Kathleen in our corner. We benefit, time and again, 
from her assistance, patience, and good nature. In fact, I've never met anyone who can issue a reminder with such a winning combination of grace and coercion.

\section{NOTES}

1 I'm indebted to Aune (1970) for much of what follows.

2 For example, that the multiple both knows and does not know who person $S$ is, or that she both believes and does not believe that she is 6 years old.

3 For more on free logic, see Lambert (2004), Morscher and Hieke (2001), and van Fraassen, 1966. And for an accessible review of many of the issues concerning nonexistent objects, see Reicher (2016).

\section{REFERENCES}

Aune, B. (1970). Rationalism, empiricism, and pragmatism: An introduction. Random House. (Reprinted by Ridgeview Publishing in 2003.)

Braude, S. E. (1986). You can say that again. Philosophic Exchange, 17, 59-78.

Braude, S. E. (1995). First person plural: Multiple personality and the philosophy of mind (Rev. ed.). Rowman \& Littlefield.

Braude, S. E. (2017). Editorial. Journal of Scientific Exploration, 31(3), 379-386.

Lambert, K. (2004). Free logic: Selected essays. Cambridge University Press.

Morscher, E., \& Hieke, A. (Eds.). (2001). New essays in free logic: In honour of Karel Lambert. Kluwer Academic.

Reicher, M. (2016). Nonexistent objects. In E. N. Zalta (Ed.), The Stanford encyclopedia of philosophy (Vol. Winter, 2016). https://plato.stanford.edu/ archives/win2016/entries/nonexistent-objects/

Thomason, R. H. (1970). Indeterminist time and truth-value gaps. Theoria, 36, 264-281.

van Fraassen, B. C. (1966). Singular terms, truth-value gaps, and free logic. Journal of Philosophy, 63, 481-495.

van Fraassen, B. C. (1968). Presupposition, implication, and self-reference. Journal of Philosophy, 65, 136-152.

Wilkes, K. V. (1988). Real people: Personal identity without thought experiments. Oxford University Press. 